\title{
Wall deposition experiments in a new spray dryer
}

\section{Huang, X.; Zhong, C.; Langrish, T. A. G.}

Drying and Process Technology Research Group, School of Chemical and Biomolecular Engineering, University of Sydney, Sydney, Australia

*E-mail of the corresponding author: timothy.langrish@sydney.edu.au

\begin{abstract}
Wall deposition tests have been conducted on a new spray-drying sytem. Solutions of salt and skim milk powder have been dried with different inlet temperatures $\left(170{ }^{\circ} \mathrm{C}\right.$ and $\left.230{ }^{\circ} \mathrm{C}\right)$ and solid contents (8.8 wt\% and $\left.30 \mathrm{wt} \%\right)$. The experiment showed that increasing the temperature caused an decrease in the amount of deposition for salt solution, but an increase for skim milk. The experiments also showed that a higher solid content caused an increase in deposition. The trends agreed with the studies using a conventional spray dryer, but the amount of deposition appeared to be lower in the new spray dryer at the same operating conditions
\end{abstract}

Keywords: Spray drying; wall deposition 


\section{Introduction}

Spray-drying techniques have been applied in a wide range of industries. One of the key issues that occurs when using spray dryers for food materials is wall deposition. During the drying process, the particles, especially if they contain sugar-rich and fat-rich food materials, may stick on the wall of the drying chamber [1]. Many workers have focused on the effects of operating conditions on the degree of wall deposition, such as the temperatures and the solid content. At a certain moisture content, the sticky point is the critical temperature at which particles transform into a sticky state due to the increase in the molecular mobility and the formation of solid bridges between particles. Studies by Roos \& Karel [2] showed a close relationship between the sticky point and the glass-transition temperature Tg of the dried materials. Solid content is another important factor affecting the formation of deposits. Goula \& Adamopoulos [3] have suggested that, for food products with higher hygroscopicity (e.g. skim milk, sucrose, tomato pulp), increasing the feed concentration increases the moisture adsorption rate on the surface of particles. Another possible effect of increasing the feed concentration is to change the particle moisture content. The moisture content within each droplets may vary with feed concentration, depending on the droplet sizes [4].

A new spray-drying system has been established in the School of Chemical and Biomolecular Engineering in the University of Sydney. The preliminary studies on the flow pattern of the spray dryer have shown that the design improved the stability of the flow field near the chamber wall, which may help to reduce wall deposition. The aim of the project is to evaluate the wall deposition performance of the new spray dryer using different feed materials and operating conditions, including inlet temperatures and feed concentrations. The experiment also compared results with previous studies using spray dryers of conventional designs.

\section{Materials and Methods}

A schematic diagram of the system is shown in Figure 1. The stainless steel chamber is insulated using glass wool insulation blankets. The drying chamber consists of two drying columns of $30 \mathrm{~cm}$ in diameter. Chamber one is $2.2 \mathrm{~m}$, and chamber two is $1.6 \mathrm{~m}$ in height. The columns comprise seven detachable sections in total, with the actual drying process starting from section 2. The chamber is fitted with a two-fluid nozzle atomizer (Buchi B-290, Switzerland). Feed solutions of all the tested materials have been introduced through the atomiser using a liquid flowrate of $27 \mathrm{ml} / \mathrm{min}$ and an atomising air flowrate of $10 \mathrm{~L} / \mathrm{min}$, which were selected according to previous experimental studies using a conventional spray dryer [5], [6]. The operating conditions for different materials have been shown in Table 1. Multiple stainless steel plates have been placed at the side wall of each section of the chamber as well as the bottoms of both columns, in order to measure the deposition fluxes. After removing the plates from all the sections, each section has been washed with water to 
dissolve all the remaining deposits. Portions of the wash solutions have been dried at $80{ }^{\circ} \mathrm{C}$ for $24 \mathrm{~h}$, in order to calculate the total mass of deposits based on the weight of the collected solutions. The total mass of deposits has been used to calculate the deposition rate, which is the total mass of deposits divided by the total sprayed solids.

Table 1 Operating conditions for different feed materials applied in the experiment.

\begin{tabular}{lcc}
\hline Feed material & Inlet temperature $\left({ }^{\circ} \mathbf{C}\right)$ & Feed concentration $(\mathbf{w t} \%)$ \\
\hline Salt & $170 / 230$ & 8.8 \\
Skim milk & $170 / 230$ & $8.8 / 30$ \\
\hline
\end{tabular}

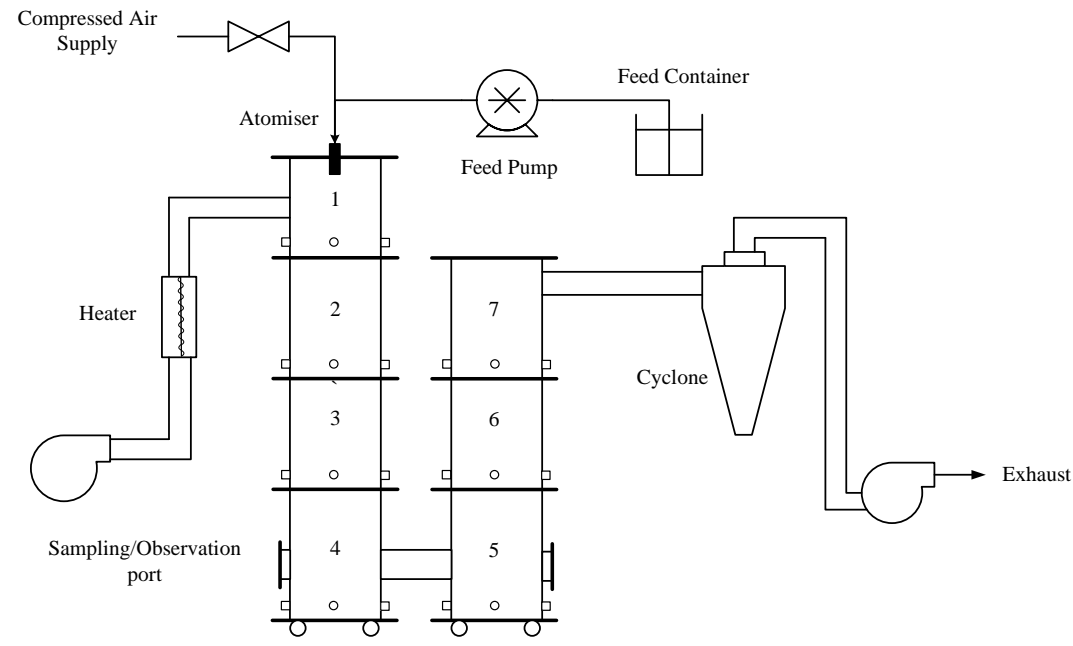

Figure 1 Schematic diagram of the new spray-drying system.

\section{Results and Discussion}

\subsection{Investigation of the influence of inlet temperature using salt and skim milk}

The inlet temperature was chosen to be the first parameter to be investigated, because it was noticed that the design features and the insulation of the new spray-drying system provided a relatively low heat loss to the environment (around $20 \mathrm{~W} / \mathrm{K}$ ). The difference in temperature profile could lead to different wall deposition behaviour compared with conventional spraydryer designs. The qualitative observations of the deposition patterns at different sections of the drying chamber have been shown in Table 5. The measurements of deposition fluxes and deposition rates have been shown in Table 2.

For the salt solutions, it can be first observed from Table 5 that there appeared to be no severe formation of wall deposits on the chamber wall, with only a thin, dusty layer observed in sections 3, 4 and 5 . Increasing the inlet temperature from $170{ }^{\circ} \mathrm{C}$ to $230{ }^{\circ} \mathrm{C}$ has shown no 
significant effect on the deposition pattern. It should be noted that, at the bottom of section 4, the deposition tended to form an evenly distributed layer, whilst at the bottom of section 5, the deposition pattern changed into spotted deposits. Such differences between indicated two different processes of forming wall deposits in the drying chamber. Kota \& Langrish [6] suggested that deposition could be formed by two mechanisms: inertial deposition, caused by the inertia of particles, and turbulent deposition, caused by the random movement of particles due to turbulence in the air flow. In chamber one (section 4), the particles from the atomiser travelled directly towards the chamber wall/bottom, then formed an evenly-distributed deposit, mainly due to particle inertia. As the particles proceeded to chamber two (section 5), the recirculation flow caused the particles to agglomerate into large particles and formed spotted deposits. From Table 2, it can also be observed that the the deposition fluxes were higher on the bottom of sections 4 and 5, which indicated that the inertial deposition may be the dominant mechanism casuing deposition. At a higher temperature of $230{ }^{\circ} \mathrm{C}$, the measurements have shown slight reductions on both the side walls and the chamber bottoms. Such reductions could be caused by a lower moisture content, thus less adhesive forces caused by liquid bridges [7].

Table 2 Wall deposition fluxes and deposition rates of 8.8 wt\% salt and skim milk feed solutions at different sections of the drying chamber.

\begin{tabular}{|c|c|c|c|c|c|}
\hline & & $\begin{array}{c}\text { Salt } \\
\left(170^{\circ} \mathrm{C}\right)\end{array}$ & $\begin{array}{c}\text { Salt } \\
\left(230^{\circ} \mathrm{C}\right)\end{array}$ & $\begin{array}{c}\text { Skim milk } \\
\left(170^{\circ} \mathrm{C}\right)\end{array}$ & $\begin{array}{c}\text { Skim milk } \\
\left(230^{\circ} \mathrm{C}\right)\end{array}$ \\
\hline \multirow{6}{*}{$\begin{array}{c}\text { Side wall } \\
\text { Deposition } \\
\text { Fluxes } \\
\left(\mathbf{g} \cdot \mathbf{m}^{-2} \cdot \mathbf{h}^{-1}\right)\end{array}$} & Section 2 & 0.5 & 0 & 0.3 & 0.5 \\
\hline & Section 3 & 2.0 & 0.7 & 2.7 & 3.0 \\
\hline & Section 4 & 1.5 & 0.3 & 1.0 & 1.0 \\
\hline & Section 5 & 2.0 & 1.6 & 5.5 & 3.5 \\
\hline & Section 6 & 1 & 0 & 1.3 & 0.7 \\
\hline & Section 7 & 0 & 0 & 0 & 0 \\
\hline $\begin{array}{c}\text { Bottom } \\
\text { Deposition }\end{array}$ & Section 4 & 10 & 11 & 7.0 & 9.5 \\
\hline $\begin{array}{c}\text { Fluxes } \\
\left(\mathbf{g} \cdot \mathbf{m}^{-2} \cdot \mathbf{h}^{-1}\right)\end{array}$ & Section 5 & 22 & 15 & 12 & 14 \\
\hline \multicolumn{2}{|c|}{ Overall average $\left(\mathrm{g} \cdot \mathrm{m}^{-2} \cdot \mathrm{h}^{-1}\right)$} & 4.9 & 3.6 & 4.0 & 4.0 \\
\hline \multicolumn{2}{|c|}{ Side wall average $\left(\mathrm{g} \cdot \mathrm{m}^{-2} \cdot \mathbf{h}^{-1}\right)$} & 1.2 & 0.4 & 2.0 & 1.4 \\
\hline \multicolumn{2}{|c|}{ Bottom average $\left(\mathrm{g} \cdot \mathrm{m}^{-2} \cdot \mathrm{h}^{-1}\right)$} & 16 & 13 & 9.3 & 12 \\
\hline \multicolumn{2}{|c|}{ Chamber 1 deposition rate (\%) } & 2.0 & 1.8 & 2.8 & 3.2 \\
\hline \multicolumn{2}{|c|}{ Chamber 2 deposition rate (\%) } & 3.4 & 1.3 & 3.3 & 4.4 \\
\hline \multicolumn{2}{|c|}{ Cyclone deposition rate (\%) } & 2.3 & 1.5 & 1.4 & 2.9 \\
\hline \multicolumn{2}{|c|}{ Total deposition rate $(\%)$} & 7.7 & 4.6 & 7.6 & 10.5 \\
\hline
\end{tabular}

In comparison with salt solutions, skim milk showed some differences in response to the increase in the inlet temperature. From Table 5, it can be seen that the deposition produced by the skim milk at $170{ }^{\circ} \mathrm{C}$ appeared to be similar to that produced by salt. As the temperature 
increased to $230{ }^{\circ} \mathrm{C}$, however, colour changes could be observed in the deposition. The brownness of the deposition indicated that Maillard reactions and possibly caramalisation may have occured at the higher temperature. Previous studies using a conventiaonl spray dryer [5] reported a deposition flux of around $16 \mathrm{~g} \cdot \mathrm{m}^{-2} \cdot \mathrm{h}^{-2}$ at the inlet temperature of $170{ }^{\circ} \mathrm{C}$, which was higher than the values measured in this work (maximum of $12 \mathrm{~g} \cdot \mathrm{m}^{-2} \cdot \mathrm{h}^{-2}$ ). The lower deposition in the new spray dryer could be caused by a more stable flow pattern and relatively smaller heat loss of the new system. However, as the inlet temperature increased to $230{ }^{\circ} \mathrm{C}$, the deposition flux in the conventional spray dryer was reported to be $8 \mathrm{~g} \cdot \mathrm{m}^{-2} \cdot \mathrm{h}^{-2}$, lower than the values measured at the bottoms of the new system. Maillard reactions and caramelisation could cause such higher deposition flux in the new dryer, as the reactions produced complex compounds [8], thus led to changes in the particle compositions and the glass transition temperature.

\subsection{Investigation of the influence of feed concentration using skim milk}

From the comparison of the wall deposits obtained at different inlet temperatures, it was strongly suggested that the higher drying temperature of $230{ }^{\circ} \mathrm{C}$ could lead to changes in the particle compositions. To avoid introducing additional variables, the investigation of the effect of feed concentration was conducted at the inlet temperature of $170{ }^{\circ} \mathrm{C}$. The qualitative observations of the deposition pattern have still been shown in Table 5, and the measurement of deposition fluxes and deposition rates have been shown in Table 3.

From Table 5, it can be observed that the bias in the deposition became more obvious at the higher feed concentration in sections 3 and 4 than that in section 5 . Four plates were placed in each of section 3, 4 and 5 in order to better interpret the distribution of the wall deposition, and the percent deviations for each section have been shown in the brackets of Table 3 . It can be seen that for the feed concentration of $8.8 \mathrm{wt} \%$, the percent deviation was found to be the highest in section 3 (96\%), and sections 4 and 5 showed a similar degree of deviation (57\% and 54\%). At the higher feed concentration, no apparent change was observed in the percent deviation in section 3 and 4 (90\% and 52\%), but a reduction was seen in section 5 from 54\% to $17 \%$. Such changes in section 5 suggested that the formation in section 5 underwent a different process from that in sections 3 and 4 . The inertial deposition due to the direct impact of the spray appeared to be the main cause of the deposition, as well as the biased deposition pattern in sections 3 and 4, regardless of the feed concentration. By contrast, with a higher feed concentration, particle of larger sizes may be less influenced by the turbulent flow, thus forming the deposition around section 5 .

The deposition fluxes measured in this experiment were again compared with the results using a conventional spray dryer [5], [6]. As shown in Table 4, the new spray dryer showed lower deposition fluxes at the same operating conditions, with the average deposition fluxes reported to be $16 \mathrm{~g} \cdot \mathrm{m}^{-2} \cdot \mathrm{h}^{-1}$ compared with $4 \mathrm{~g} \cdot \mathrm{m}^{-2} \cdot \mathrm{h}^{-1}$ at a concentration of $8.8 \mathrm{wt} \%$, and 130 
$\mathrm{g} \cdot \mathrm{m}^{-2} \cdot \mathrm{h}^{-1}$ compared with $50 \mathrm{~g} \cdot \mathrm{m}^{-2} \cdot \mathrm{h}^{-1}$ with a $30 \mathrm{wt} \%$ feed solution. Despite the overall lower deposition flux, the new drying system showed the increasing trend similar to the previous studies, as shown in Table 4. There are several reasons that could lead to the increaing wall deposition fluxes: 1) higher the specific moisture content due to larger droplet sizes; 2) the hygroscopicity of skim milk increases with the solid content, which could hinder the drying process; 3) particles with higher solid content tended to form crust of higher thickness, which could reduce the evaporation of moisture within the crust.

Table 3 Wall deposition fluxes and deposition rates of $8.8 \mathrm{wt} \%$ and $30 \mathrm{wt} \%$ skim milk feed solutions at different sections of the drying chamber. Inlet temperature $=170^{\circ} \mathrm{C}$.

\begin{tabular}{|c|c|c|c|}
\hline & & $\begin{array}{l}\text { Skim milk } \\
\text { (8.8 wt \%) }\end{array}$ & $\begin{array}{c}\text { Skim milk } \\
\text { (30 wt \%) }\end{array}$ \\
\hline \multirow{6}{*}{$\begin{array}{c}\text { Side wall } \\
\text { Deposition } \\
\text { Fluxes } \\
\left(\mathbf{g} \cdot \mathbf{m}^{-2} \cdot \mathbf{h}^{-1}\right)\end{array}$} & Section 2 & 0.3 & 6 \\
\hline & Section 3 & 2.7 (96\%) & $63(90 \%)$ \\
\hline & Section 4 & $1.0(57 \%)$ & $17(52 \%)$ \\
\hline & Section 5 & $5.5(54 \%)$ & $98(17 \%)$ \\
\hline & Section 6 & 1.3 & 13 \\
\hline & Section 7 & 0 & 5 \\
\hline $\begin{array}{c}\text { Bottom } \\
\text { Deposition }\end{array}$ & Section 4 & 7.0 & 121 \\
\hline $\begin{array}{c}\text { Fluxes } \\
\left(\mathrm{g} \cdot \mathrm{m}^{-2} \cdot \mathbf{h}^{-1}\right)\end{array}$ & Section 5 & 12 & 74 \\
\hline \multicolumn{2}{|c|}{ Overall average $\left(\mathrm{g} \cdot \mathrm{m}^{-2} \cdot \mathbf{h}^{-1}\right)$} & 4.0 & 50 \\
\hline \multicolumn{2}{|c|}{ Side wall average $\left(\mathrm{g} \cdot \mathrm{m}^{-2} \cdot \mathrm{h}^{-1}\right)$} & 2.0 & 33 \\
\hline \multicolumn{2}{|c|}{ Bottom average $\left(\mathrm{g} \cdot \mathrm{m}^{-2} \cdot \mathrm{h}^{-1}\right)$} & 9.3 & 98 \\
\hline \multirow{2}{*}{\multicolumn{2}{|c|}{$\begin{array}{l}\text { Overall average w.r.t solid flowrate }\left(\mathrm{g} \cdot \mathrm{m}^{-2}\right) \\
\text { Side wall average w.r.t solid flowrate }\left(\mathrm{g} \cdot \mathrm{m}^{-2}\right)\end{array}$}} & 0.026 & 0.10 \\
\hline & & 0.013 & 0.069 \\
\hline \multicolumn{2}{|c|}{ Bottom average w.r.t solid flowrate $\left(\mathrm{g} \cdot \mathrm{m}^{-2}\right)$} & 0.065 & 0.20 \\
\hline \multicolumn{2}{|c|}{ Chamber 1 deposition rate (\%) } & 2.8 & 3.2 \\
\hline \multicolumn{2}{|c|}{ Chamber 2 deposition rate (\%) } & 3.3 & 4.4 \\
\hline \multicolumn{2}{|c|}{ Cyclone deposition rate (\%) } & 1.4 & 2.9 \\
\hline \multicolumn{2}{|c|}{ Total deposition rate $(\%)$} & 7.6 & 10.5 \\
\hline
\end{tabular}

Note: values in the brackets show percentages of the deviation with respect to the average deposition fluxes of the plates in the same chamber.

Table 4 Average deposition fluxes of skim milk solutions dried at inlet temperature of $170{ }^{\circ} \mathrm{C}$ using a conventional spray dryer and the new spray-drying system in this work.

\begin{tabular}{|c|c|c|}
\hline & $\begin{array}{c}\text { Feed concentration } \\
(\%)\end{array}$ & $\begin{array}{c}\text { Average deposition } \\
\text { flux }\left(\mathbf{g} \cdot \mathbf{m}^{-2} \cdot \mathbf{h}^{-1}\right)\end{array}$ \\
\hline Ozmen \& Langrish [5] & 8.8 & 16 \\
\hline Kota \& Langrish [6] & 30 & 130 \\
\hline \multirow[t]{2}{*}{ This work using the new spray dryer } & 8.8 & 4.0 \\
\hline & 30 & 50 \\
\hline
\end{tabular}


Table 5 Qualitative observations of wall depositions formed at different sections of the drying chamber.

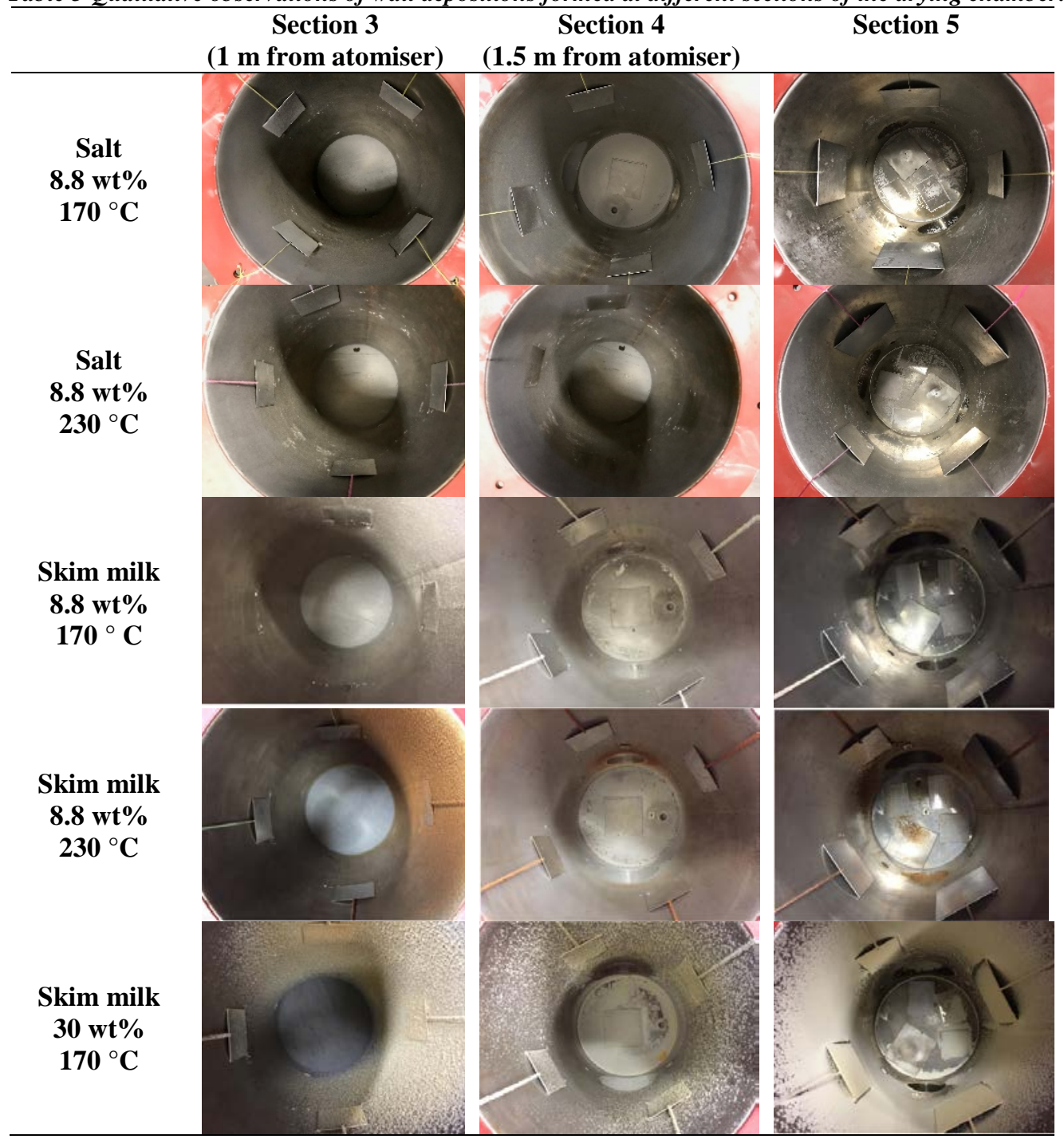

\section{Conclusion}

Wall deposition tests have been conducted on a a new spray dryer in order to investigate its performance at different operating conditions, and compare it with a conventional design. The increase in the inlet temperature from $170{ }^{\circ} \mathrm{C}$ to $230{ }^{\circ} \mathrm{C}$ has caused a slight reduction in wall deposition rate for salt solutions, but an increase in the value for skim milk solutions. Such a difference could be caused by the change in the composition of skim milk deposits as a result of Maillard reactions. The experiments with different feed concentrations showed an 
increase in wall deposition when the solid content increased from 8.8 wt\% to $30 \mathrm{wt} \%$. Such an increasing trend agreed with the previou studies using a conventional spray dryer, although the actual amount of wall deposition appeared to be lower in the new spray dryer. Overall, the experiments provided some valuable information to improve the design of the new system.

\section{References}

[1] B. R. Bhandari and T. Howes, "Relating the Stickiness Property of Foods Undergoing Drying and Dried Products to their Surface Energetics,” Dry. Technol., vol. 23, no. 4, pp. 781-797, 2005.

[2] Y. Roos and M. Karel, “Applying state diagrams to food processing and development.," Food Technol., vol. 45, no. 12, pp. 66, 68-71, 1991.

[3] A. M. Goula and K. G. Adamopoulos, "Spray drying of tomato pulp: Effect of feed concentration,” Dry. Technol., vol. 22, no. 10, pp. 2309-2330, 2004.

[4] L. Tajber, O. I. Corrigan, and A. M. Healy, "Spray drying of budesonide, formoterol fumarate and their composites-II. Statistical factorial design and in vitro deposition properties,” Int. J. Pharm., vol. 367, no. 1-2, pp. 86-96, 2009.

[5] L. Ozmen and T. A. G. Langrish, "An Experimental Investigation of the Wall Deposition of Milk Powder in a Pilot-Scale Spray Dryer,” Dry. Technol., vol. 21, no. 7, pp. 1253-1272, 2003.

[6] K. Kota and T. A. G. Langrish, "Fluxes and Patterns of Wall Deposits for Skim Milk in a Pilot-Scale Spray Dryer,” Dry. Technol., vol. 24, no. 8, pp. 993-1001, 2006.

[7] M. J. Hanus and T. A. G. Langrish, "Re-entrainment of wall deposits from a laboratoryscale spray dryer,” Asia-Pacific J. Chem. Eng., vol. 2, no. 2, pp. 90-107, 2007.

[8] S. Martins, S. I. F. S. Martins, and W. M. F. Jongen, “A review of Maillard reaction in food and implications to kinetic modelling A review of Maillard reaction in food and implications to kinetic modelling,” Trends Food Sci. Technol., vol. 11, pp. 364-373, 2001. 